\title{
Emergency contraception as an element in the care of rape victims
}

Ricardo Vernon

Raffaela Schiavon

Silvia Elena Llaguno

Follow this and additional works at: https://knowledgecommons.popcouncil.org/departments_sbsr-rh

Part of the Health Services Research Commons, International Public Health Commons, and the Women's Health Commons

How does access to this work benefit you? Let us know!

\section{Recommended Citation}

Vernon, Ricardo, Raffaela Schiavon, and Silvia Elena Llaguno. 1997. "Emergency contraception as an element in the care of rape victims," INOPAL III Final Report. Mexico City: Population Council. 


\title{
EMERGENCY CONTRACEPTION AS AN ELEMENT IN THE CARE OF RAPE VICTIMS
}

\author{
Prepared by \\ Ricardo Vernon \\ Rafaella Schiavon \\ Silvia Elena Llaguno
}

\begin{abstract}
With the collaboration of
Attorney General Offices of the Federal District and the states of Hidalgo, Tlaxcala, Morelos, Oaxaca, Veracruz, Mexico, Jalisco, and MEXFAM, CEPAHR, SIPAM, Sí Mujer, ADIVAC, AVISE, COVAC, FAVI and COPAS.
\end{abstract}

Mexico City, Mexico, July 1997. 
Even though in most states in Mexico abortion is excluded as a crime in the case of pregnancies resulting from rape, the legislation does not specify the norms by which women can obtain a legal abortion, a fact which makes it extremely difficult to choose this alternative. A partial solution to unwanted pregnancies from rape would be to provide emergency contraception to raped women.

The purpose of this project was to test the feasibility and acceptability of emergency contraception as an element in the care of rape victims. Psychologists of the Federal District's Attorney General Office in Mexico were trained to provide information on emergency contraception to women who reported a rape at four public ministry agencies specialized in sexual crimes, and at the Support Therapy Center, where victims are referred for psychological counseling. In addition, eleven medical back-up referral centers were established with the assistance of MEXFAM, CEPAHR and SIPAM, three NGOs that provide services en Mexico City's metropolitan area. According to the AGO's statistics, 82 rape victims were provided this information between July, 1997 and March, 1997, about 10\% of all the women aged 13-55 who reported a vaginal rape during the period. The proportion of reported rapes that ended in a pregnancy decreased from $9.8 \%$ during the 18 pre-intervention months to $7.4 \%$ during the nine intervention months. A total of 22 women attended the referral centers and an additional eleven women received information through the telephone.

To scale up the strategy, workshops were provided to representatives from different state Attorney General Offices and feminist NGOs. By the end of the project, the AGOs of the states of Hidalgo, Jalisco, Tlaxcala, Morelos, Oaxaca, Veracruz and Mexico, as well as of five additional feminist NGOs (ADIVAC, AVISE, COVAC, COPAS and FAVI) had also incorporated emergency contraception as an element in the care of rape victims. In the two months after the workshop, these organizations had provided verbal information on emergency contraception to 248 women, and had handed out the brochure to 411 women. In addition, most of them had given talks and replicated the workshop. 
TABLE OF CONTENTS

$\begin{array}{ll}\text { I. BACKGROUND } & 1\end{array}$

II. PROBLEM STATEMENT 2

III. PROBLEM SOLUTION

IV. OBJECTIVES 3

V. METHODOLOGY 4

VI. OPERATIONS RESEARCH ACTIVITIES AND RESULTS 4

6.1 Development of IEC and Data Collection Materials 4

6.2 Training of the Staff of the Support Therapy Center 6

6.3 Establishment of Referral Centers 8

6.4 Results 8

VII DISSEMINATION AND SCALING UP 11

7.1 Dissemination Activities 11

7.2 Scaling-up Activities 13

VIII RECAPITULATION 16

$\begin{array}{ll}\text { IX REFERENCES } & 18\end{array}$

$\begin{array}{llr}\text { X APPENDICES } & 19\end{array}$ 


\section{BACKGROUND}

Title XV of the Federal District=s Penal Code considers as sexual offenses, among others, the following:

$\mathrm{P} \quad$ Sexual harassment, defined as repeatedly besieging a person of any sex, using a hierarchical position derived from work, academic or domestic relations or any other implying subordination.

P Sexual abuse, defined as the execution of a sexual act without the consent of a person and without the purpose of reaching coitus.

P Rape (estupro), defined as coitus with a person older than 12 years of age and younger than 18 years of age, obtaining consent by means of deceit.

P Rape (violación), defined as coitus with a person of any sex by means of physical or moral violence, the vaginal or anal introduction of any element other than the penis, coitus with a person under 13 years of age, and coitus with a person without the capacity of understanding the meaning of the act or by any other cause that impedes resisting the act.

When a sexual offense is suffered, the victim must report it to an agency of the FDAGO to set in motion the legal process to detain the aggressor and, in the case of sexual crimes, to refer the victim to specialized care centers. In the Federal District, reports on sexual offenses must be presented in any of the four Specialized Agencies in Sexual Crimes (SASC) of the Federal District=s Attorney General Office (FDAGO). These specialized agencies are open 24 hours a day, are staffed only by females, and their staff includes physicians and psychologists. In addition, the four SASCs refer all women filing reports to the Support Therapy Center (STC) where specialized psychologists provide care to victims until they recover their mental health. The STC also refers women needing health services to appropriate health care facilities, and provides legal assistance to those needing it.

During the period January-September, 1995, 2,690 sexual crime reports were presented en the four SASCs. The sexual crime with the highest incidence was rape, with $47.5 \%$ of the cases, followed by sexual abuse, with $27.7 \%$ of the cases. Of the 1,277 rape reports, 822 were reports for vaginal rape in women between 13 and 55 years of age, and of these, 86 resulted in a pregnancy. In addition, there was a loss of follow-up in 288 cases in which pregnancy was considered a possible result. Seventy two percent of rape reports were presented within the first 72 hours following the rape. 
During January-September, 1995, the Support Therapy Center (STC) cared for 478 rape victims. In addition, its Hotline for Sexual Crime Victims (CETATEL) received 1,449 calls, of which 319 concerned rapes.

\section{PROBLEM STATEMENT}

The Federal District=s Penal Code considers in articles 329 to 334 the conditions under which induced abortion is punishable. Article 333 excludes as a crime abortion Acaused only by the neglect of the pregnant women and also in the case that the pregnancy is a result of rape.@ However, the legislation does not specify the norms that a woman in these situations can follow in order to obtain a legal abortion, a fact which most of the times leave women without recourse. In practice, the FDAGO refers for abortions at public hospitals only a fraction of the women who report a pregnancy resulting from rape. During January-September 1995, only three women were referred for legal abortions. Thus, 83 women were not able to interrupt an unwanted pregnancy resulting from rape, as provided by the law.

The obstacles to legally interrupting a pregnancy resulting from rape are of a practical nature (such as the time needed to comply with legal procedures, the referral to the appropriate institution, the scheduling of the surgery) but also of a psychosocial nature, since the weight of making the decision falls on the psychologically harmed victim. Thus, it is not rare that the pregnancy gets to term.

In order to protect the mental and physical health of the woman, and avoid the economic, psychological and social costs of a pregnancy or an abortion resulting from rape, a strategy should be developed to prevent those pregnancies and abortions.

\section{PROBLEM SOLUTION}

A partial solution to the problem of unwanted pregnancies resulting from rape would be the use of emergency contraception as an element in the comprehensive care of victims of this crime. Emergency contraception is the use of contraceptive methods after an unprotected sexual relationship. By definition, these methods are Anot abortifacient, they act preventing an unwanted pregnancy"1.

The most common emergency contraception method involves the use of combined oral contraceptives: women who have unprotected sexual relationships may avoid an unwanted pregnancy swallowing as soon as possible, and not after 72 hours of the sexual relation, two contraceptive pills with $50 \mathrm{mcg}$ ethynil estradiol $/ 250 \mathrm{mcg}$ levonorgestrel followed by two additional pills after 12 hours. In the case of low dose pills ( $30 \mathrm{mcg}$ ethynil estradiol/150 mcg levonorgestrel), four pills must be swallowed in the first 72 hours after the unprotected sexual relation, followed by four additional pills after 12 hours. There are no known counter indications for these regimes, and they are $98 \%$ effective in the prevention of pregnancies. Secondary effects include nausea (in approximately $50 \%$ of the cases), irregular uterine bleeding and tenderness of 
breasts $^{2}$. Because these side effects are very common, counseling for women should include correct use of the emergency contraceptive method; possible side-effects and their management; and family planning methods for preventing pregnancies in the future.

Given that $71.6 \%$ of rape victims present the report of the crime at any of the four SASCs in the first three days after the rape, emergency contraception could help prevent over two thirds of the pregnancies resulting from rapes reported to the FDAGO. Accessibility to the method would not be a problem, since combined oral contraceptives are widely available in pharmacies, as well as in social security clinics and health centers. However, emergency contraception is relatively unknown by service providers, making it necessary to train service providers both in the clinical management of users, as well as in counseling techniques for rape victims.

\section{OBJECTIVES}

The main objective of this project was to test the use of emergency contraception as an element in the care of rape victims in Mexico City. Specific objectives included the following:

1. Test the feasibility, acceptability and effectiveness of providing information on emergency contraception to rape victims that present a report in the four FDAGO agencies specialized in sexual crimes.

2. Disseminate and scale up the strategy for providing emergency contraception as an element in the care of rape victims among Attorney General Offices of the different states of Mexico, as well as among non governmental organization who provide services for abused women.

\section{METHODOLOGY}

This operations research was a demonstration project in which no formal experimental design was used.

Given the restricted access to rape victims and the need for confidentiality of data, the number of rape victims who were advised by the psychologists on emergency contraception, the number of medical back-up referral centers and the number of women who attended the referral centers were used as the main dependent variables to evaluate the strategy to introduce emergency contraception as an element in the care of rape victims. This information was collected by the staff of the FDAGO and of the referral clinics and physicians.

To evaluate the second objective, the number of dissemination and institutionalization activities, as well as the impact of these activities were used.

In the following section, further information on variables, data collection instruments and results of the activities are presented. 


\section{OPERATIONS RESEARCH ACTIVITIES AND RESULTS}

Three main activities were carried out to test the use of emergency contraception as an element in the care of rape victims: the development of IEC and evaluation materials, training of the psychologists at the Support Therapy Center of the FDAGO, and the establishment of a referral system for medical back-up. In the following three sections of this chapter, each of these activities are described. The last section of this chapter presents the results.

\subsection{Development of IEC and Data Collection Materials}

IEC materials developed for the project included a brochure on emergency contraception for victims, a leaflet for screening and counseling women, and a package with photocopies with different articles on emergency contraception.

The brochure is presented as Appendix 1. The aim of this brochure is to give all the basic information that a raped women may need to decide if she should use emergency contraception and to enable her to follow the treatment if she decides to do so, including form of use, effectiveness, and side effects and their management. A first draft of the brochure was pretested during the training sessions of the psychologists of the FDAGO, who were asked to review the draft brochure and to show it to some patients to see if it was understood. The draft was also circulated among different physicians and editors and their comments were incorporated. The main criticism of the brochure was that no institution signed it. Neither the Attorney General Office or the General Direction of Reproductive Health wanted to appear as sources of the brochure, but a few months later MEXFAM agreed to sign it. Other recommendations included changing the design, using colors, modify the wording, dropping one brand of pills that did not have the formulation indicated in the brochure, dropping counter-indications, and including such information as the need to avoid sexual relations or using contraception until the return of menses.

The counseling guide for victims consisted of two type-written pages in which step by step suggestions on how to screen women and provide counseling on emergency contraception were listed. The counseling guide is presented as Appendix 2.

Finally, participants were given a package with photocopies of different articles in journals, manuals and leaflets on emergency contraception. It was expected that these materials would assure participants of the scientific validity of emergency contraception, as well as references they could consult in case of doubts.

Regarding the data collection materials, four forms were designed to collect information on the characteristics of women filing reports for rape, and the number who received information at the public ministry agencies, the Support Therapy Center and the hotline for sexual victims. Follow-up forms to assess the use of emergency contraception were also designed. However, a 
follow-up conducted five months after the beginning of the intervention showed that the psychologists were afraid of using these forms and preferred to keep personal records. A second, simplified version was adopted in December, 1996, but in early 1997 a new director of the Support Therapy Center was appointed, and one of her first decisions was to change the information system that was being used to reflect changes in the service delivery system which are explained in section 6.4. In this new information system, the Afirst contact@ form includes an item which asks if the woman was given information on emergency contraception (see Appendix 3). This shows that by that time emergency contraception had for all practical purposes been institutionalized at the FDAGO .

\subsection{Training of the Staff of the Support Therapy Center}

The objective of the training was to prepare the psychologists of the Support Therapy Center so that they could screen women in need of information on emergency contraception and to give them the appropriate information on form of use and side-effects. This information was to be provided both at the four specialized public ministry agencies (where victims of rape file their reports) as well as at the Support Therapy Center, where psychological treatment is provided to the victims.

The training sessions had a duration of four hours. Four different sessions were conducted in June 17 and June 24, 1996. Besides the psychologists, some legal physicians of the specialized public ministry agencies and the telephone operators of CETATEL, the hotline for sexual crime victims, attended the sessions. Finally, a few staff members from the $\mathrm{MOH}=\mathrm{s}$ General Direction for Family Planning and feminist NGOs were invited and attended these sessions. The total number of persons trained was approximately 97, with each session attended by about 15 - 30 persons. In addition to the initial training sessions, one session was conducted in February, 1977, to train 33 new staff members who had arrived at the Support Therapy Center as part of the reorganization that took place in the beginning of the year.

The following topics were included in the training:

1) Introduction and presentation of the project

2) History of emergency contraception

3) Emergency contraception: treatments and side effects.

4) Screening rape victims for emergency contraception.

5) Counseling in emergency contraception for rape victims.

6) Use of data collection forms to follow up the results of the project 
A questionnaire was applied at the beginning of the sessions to assess the knowledge and attitudes of attendees toward emergency contraception. A copy of the questionnaire is presented as Appendix 4. A total of 62 attendees responded the questionnaire, of which 44 were psychologists, seven social workers, seven physicians and four of other professions. Seventy two percent said they had heard of emergency contraception, including $75 \%$ of the psychologists. Sixty two percent of the total correctly said emergency contraception consisted in preventing a pregnancy in the first few days after unprotected sex. Fifty percent of the total knew contraceptive pills could be used for emergency contraception purposes. Only two of them thought that emergency contraception worked as a micro abortifacient, with the reminder answering that it worked by preventing implantation or fecundation. Thirteen percent knew somebody who had used emergency contraception, most of them psychologists.

In the second part of the questionnaire, a brief explanation of what emergency contraception is was provided and the attitudes towards it was assessed. Eighty nine percent said they would completely agree or agree to recommend emergency contraception to women who filed a report for rape. When asked in which cases should emergency contraception be recommended, $77 \%$ said it should be provided to any women in need of it. Fifty six percent said the treatment should be made available in centers that attended raped women, hospitals and in all clinics offering family planning, and $26 \%$ thought that in addition, it should be offered in pharmacies and schools. Sixty one percent thought information on emergency contraception should be disseminated through the mass media, and $27 \%$ thought that only physicians should be informed through professional journals and meetings.

Even though the results of this questionnaire showed a favorable attitude towards the use of EC as an element in the care of rape victims, during the training sessions several participants, specially physicians, showed large concerns of the implications and potential consequences of giving information on emergency contraception in the public ministry agencies. The main concern was the potential legal consequences, given that they had not received any written order requesting them to provide this treatment. A second source of concern was that the brochure that was presented to them was not signed by any institution. A third source of concern for psychologists was that they felt that, since they were not physicians, they could be accused of prescribing drugs without a licence. In reality, their main concern was to be accused of performing abortions.

As explained in the previous section, during the training, participants were also handed out the brochure on emergency contraception to be give to women, a counseling guide, data collection forms and a set of photocopies of articles on emergency contraception.

\subsection{Establishment of Referral Centers}

One of the initial project objectives was to establish referral sites at $\mathrm{MOH}$ health centers or hospitals. Given that emergency contraception is not mentioned in the Mexican Family Planning Norms and the uncertainties of its legal status, the General Direction for Reproductive Health (DGSR) was hesitant to implement this activity. Although the head of the MOH services 
of the Federal District was initially supportive of conducting the activity, a request for clarification of the status of EC to the DGSR failed to elicit a response and action was delayed.

For these reasons, MEXFAM and two other small NGOs (SIPAM and CEPARH) were approached to see if they would like to participate as referral sites. They all agreed, and training of 35 physicians of 15 clinics and offices was conducted on September 17, 1996. Drs. Raffaela Schiavon, project consultant, and Josué Garza, director of CEPARH and a very respected researcher in biology of reproduction, presented aspects related to the history, medical uses and current research on EC. Other presentations were made by the head of the Support Therapy Center (on the realities of sexual offenses in Mexico); by Esperanza Reyes, a psychologists who works for COVAC, a feminist organization, on psychological aspects of raped women; by Deyanira Herrera, of COVAC, on legal issues and legal assistance for raped women; by Gabriela Infante, of GIRE, on the reproductive rights of raped women; and by Ricardo Vernon, on data collection and reporting.

Surprisingly enough, many of the same reactions observed in the training of psychologists were observed among participants, not only by some MEXFAM community physicians but also by some mid-level managers of the central staff. Nevertheless, the staff of five clinics and six community physicians were enthusiastic about the opportunity to participate as a referral center.

To facilitate the referrals, the addresses of these clinics and physicians were printed in a slip that was attached to the brochures for women (see Appendix 5). In this way, the women received both the information needed to use emergency contraception on their own, as well as a list of physicians spread around Mexico City's metropolitan area which they could visit to clarify any doubts.

\subsection{Results}

Information giving activities started in July, 1996. As explained, the psychologists were supposed to provide information in the first contact the women had either at the public ministry agencies or at the Support Therapy Center. However, in the second month of activities it became clear that very few of the psychologist working at the public ministry agencies were giving the information to women. Their reluctance to do so stemmed from not having direct written orders from the appropriate authorities and their fear of consequences. Other factors included the lack of a sponsoring institution of the brochure and the fear of prescribing drugs. Nevertheless, at this stage, nine women had received information at the Support Therapy Center, all of them had seen their menses return, and all of them were reportedly very grateful for the information given. All women were single, six were 17 or less years of age, all were students or unemployed, and all had at least some junior high schooling.

In September, the final version of the brochure sponsored by MEXFAM was printed and distributed, and the medical back-up referral sites were established. In October, 1996, a follow up visit was made to twelve psychologists who worked in three different shifts at the public ministry agencies. During the interviews, it was found that only four said they had given the information 
to women, and two more said that they had not given the information but referred the women to the Support Therapy Center. These last two said they would start giving the information given the new brochure and the existence of referral sites, and one which had not participated said she would start providing the information. All of them considered it a great advance the establishment of the referral centers and the changes in the brochure. Five said that greater support from the Support Therapy Center was needed (i.e., written instructions to provide EC). It was also observed that the psychologists were not filling out the data collection forms, but were keeping private records of the women they advised about emergency contraception. In all, these women said they had given the information to 25 women, but only one had kept records. Of her 15 clients, 12 had reported the return of menses and 3 had not reported back their status. Thus, apparently 34 women had been given the EC treatment, of which 20 had been followed up. No pregnancies had resulted in these cases. Follow-up visits showed an increased rate of participation of the psychologists after the referral centers were established.

Table 1 shows that according to FDAGO service statistics, a total of 82 women were given information on emergency contraception between July, 1996 and March, 1997. In the first trimester of 1997, there was a decreased number of rapes reported at the Support Therapy Center. At this time, psychologists working at the public ministry agencies were redeployed to the Support Therapy Center and started going to the public ministry 
TABLE 1

RAPES, PREGNANCIES, REQUESTS FOR ABORTION, LEGAL ABORTIONS AND WOMEN ADVISED ON EMERGENCY CONTRACEPTION ACCORDING TO THE SUPPORT THERAPY CENTER=S SERVICE STATISTICS

\begin{tabular}{|l|c|l|l|l|c|}
\hline \multirow{2}{*}{\multicolumn{1}{|c|}{ VARIABLE }} & \multicolumn{5}{c|}{ PERIOD } \\
\cline { 2 - 6 } & \multicolumn{2}{|c|}{1995} & \multicolumn{2}{c|}{1996} & 1997 \\
\cline { 2 - 6 } & JAN-JUN & JUL-DEC & JAN-JUN & JUL-DEC & JAN-MAR \\
\hline $\begin{array}{l}\text { NUMBER OF RAPES } \\
\text { REPORTED BY WOMEN } \\
13-55 \text { YEARS OF AGE }\end{array}$ & 550 & 557 & 558 & 603 & 220 \\
\hline $\begin{array}{l}\text { NUMBER OF } \\
\text { PREGNANCIES }\end{array}$ & 60 & 42 & 62 & 47 & 14 \\
\hline $\begin{array}{l}\text { LEGAL ABORTIONS } \\
\text { REQUESTED }\end{array}$ & NA & NA & NA & 11 & 4 \\
\hline $\begin{array}{l}\text { LEGAL ABORTIONS } \\
\text { NA }\end{array}$ & NA & NA & NA & 2 \\
\hline $\begin{array}{l}\text { WOMEN COUNSELED } \\
\text { ON EMERGENCY } \\
\text { CONTRACEPTION }\end{array}$ & - & - & - & 60 & 22 \\
\hline
\end{tabular}

agencies only when informed of the presence of a woman filing a report for sexual abuse or for rape. This apparently made them

less effective in providing services. However, as in the previous period, about $10 \%$ of the women who reported a rape received information on emergency contraception. Even though this seems to be a small percentage of the cases, it should be considered that the contraceptive prevalence rate in Mexico City is of about $71 \%$ of married women of fertile age, that the age range reported by the service statistics is 13 to 55 years of age, and that about $27 \%$ of women file their reports for rape more than three days after the rape, so perhaps a high proportion of women who could actually benefit from the information received it. Unfortunately, no information regarding the number of potential beneficiaries is available to assess the coverage of women in actual need.

Table 1 also shows an apparent decline in the proportion of rapes resulting in pregnancies, from about $9.8 \%$ of all rapes reported during January 1995-June 1996, to $7.4 \%$ during July 1996-March 1997. The effects of providing information on emergency contraception 
on the number of abortion requests cannot be assessed given the unavailability of this information for the pre-intervention period.

Regarding the medical back-up referral centers, until May, 1997, seven of the 11 reference clinics and physicians had provided services to 22 women and had provided information through the telephone to 11 women. Only eight women had returned for follow up, and no pregnancies had resulted. The remaining four reference centers had not received women or telephone calls of women requesting emergency contraception services.

\section{DISSEMINATION AND SCALING UP}

As part of this project, a large effort was made to disseminate the information on emergency contraception and to scale-up the introduction of emergency contraception as an element in the care of rape victims.

\subsection{Dissemination Activities}

Although not in the scope of work of this project, dissemination activities were carried out on the basis of opportunities that were detected. These included the following:

a. E-mail: twenty-five organizations listed in one server as feminist and health/social development organizations were sent a letter entitled AYou can help us prevent pregnancies from rape@ (See Appendix 6). The letter offered training and materials to those organizations who attended rape victims and gave information on emergency contraception. Six organizations responded to the offer and were sent materials. One organization posted the letter and the project brochure on their electronic conference and another published the letter in the January, 1997, issue of Fem magazine, a feminist magazine in Mexico. The largest news group in Mexico on reproductive health, Genero.Venus, also requested the brochure to post it after they read this letter.

b. Letters to editors: in October, 1996, two national newspapers published news items in which it was said that the church approved the use of the pill in certain cases, such as sexual violence. This opportunity was used to send one letter to each of the editors in which information on emergency contraception was provided and in which persons willing to help prevent pregnancies from rape were invited to participate in our project. Two persons responded to the invitation, including the manager of a telephone hot line in the city of Cuernavaca who wanted to include the information on emergency contraception. The articles and letters to the editors are presented as Appendix 7.

c. Publication of the emergency contraception brochure in Alternativas: the November, 1996, issue of Alternativas, the INOPAL III newsletter with a circulation of 2,000 copies in Latin America, invited family planning organizations to establish a program to provide emergency contraception to rape victims. In addition, it published a brochure for rape 
victims that could be readily photocopied (see Appendix 8). Although Alternativas offered to customize the brochure to the needs of those interested in establishing these services, no responses were obtained.

d. Mailing to justice, family planning and feminist organizations: in June, 1997, packages with a letter inviting them to establish emergency contraception services for rape victims and a set of materials on emergency contraception were mailed to 185 justice, family planning and feminist organizations in Latin America and the Caribbean, including Attorney General Offices of the different states in Mexico, the IPPF affiliates, and a large variety of feminist organizations. The package included 25 project brochures, the Outlook issue on emergency contraception, two MEXFAM and GAP issues on emergency contraception, the IPPF Medical Bulletin on emergency contraception and the chapter on emergency contraception in Contraceptive Technology. At the time this report was prepared, one month after the mailing, three responses had been received, two acknowledging the mailing, and one from a researcher at the Colegio de Mexico, who had photocopied the materials and included the topic for discussion in a working group on domestic violence and health.

e. Presentation in conferences and meetings: the characteristics and preliminary results of the project have been or will be presented at the international meetings on emergency contraception conducted at the Population Council in New York on October, 1996 and 1997; the National Public Health Congress held in Cuernavaca, Mexico, in March, 1997; the annual meeting of the Social Workers in Jalisco and at ITAM's Violence and Woman Week, in September,1997: and the annual meeting of the Colegio de Psicólogos, in October, 1997.

\subsection{Scaling-up Activities}

Scaling-up activities included mostly workshops for justice and feminist organizations, including the following:

a. Workshops for justice organizations: three workshops for the staff of the Attorney General Offices, MOH staff and NGOs were conducted in the states of Coahuila and Hidalgo. In Coahuila, in the cities of Saltillo and Torreón, the workshops were attended by public ministry agents, MOH staff and staff of Sí Mujer, a feminist organization that provides health services. Representatives from the AGO of the nearby states of Nuevo Leon and Durango were invited to these workshops. Although only four rape victims had been referred by June, 1997 (and only one of them was in the first three days), MOH participants in Torreón reported having given five talks on emergency contraception to an approximate audience of 600 physicians, social workers and staff of the public ministry agencies in the city. In Hidalgo, a workshop was conducted in February, 1997, for staff of the state's AGO, MOH and the University of Hidalgo. The strategy was institutionalized. By May, 1997, 10 women had received emergency contraception and no pregnancies had resulted from the rapes. 
b. Workshops for feminist organizations: these have included 1) a workshop for the staff of FAVI, an NGO in Mexico City that provides services for victims of violence; 2) a workshop for representatives of 10 feminist organizations coordinated by GIRE. Gire incorporated the topic of emergency contraception on two workshops on abortion (funded by the McArthur Foundation) for $\mathrm{MOH}$ and social security staff in the states of Veracruz and Chihuahua.

c. End of Project Conference: the last activity conducted by the project was a workshop attended by 65 representatives from eight state AGOs and 10 feminist organizations from seven states near Mexico City. Presenters at the workshop included Rafaella Schiavon, project consultant, and representatives from organizations that had participated in project activities, such as the AGOs of the Federal District and Hidalgo, MEXFAM, FAVI, GIRE and CEPARH. Participants were given a package of printed materials on emergency contraception, and a set of slides to replicate the most important presentations in their organizations and cities. The workshop was held in May, 1997. To evaluate the workshop, a questionnaire was mailed to all participants (see Appendix 9). Thirty participants from 18 different organizations had responded the questionnaire five weeks after the mailing (mail delivery takes two weeks in Mexico, so respondents had had the questionnaire only for a week). Seven of the organizations were state AGO; seven were feminist organizations, and four were educational or reproductive health organizations. Tables 2 and 3 present the main results of this questionnaire. 
TABLE 2

NUMBER OF PARTICIPANTS WHO HAVE CONDUCTED DIFFERENT EMERGENCY CONTRACEPTION ACTIVITIES AND NUMBER BENEFICIARIES OF THIS ACTIVITIES BY TYPE OF ORGANIZATION OF THE END-OF-PROJECT PARTICIPANT

\begin{tabular}{|c|c|c|c|c|c|c|c|c|}
\hline \multirow{3}{*}{ ACTIVITY } & \multicolumn{8}{|c|}{ TYPE OF ORGANIZATION } \\
\hline & \multicolumn{2}{|c|}{$\begin{array}{l}\mathrm{JU} \\
\mathrm{STICE} \\
(\mathrm{N}=19)\end{array}$} & \multicolumn{2}{|c|}{$\begin{array}{l}\text { FEMINIST } \\
(\mathrm{N}=10)\end{array}$} & \multicolumn{2}{|c|}{$\begin{array}{l}\text { OTHER } \\
(\mathrm{N}=4)\end{array}$} & \multicolumn{2}{|c|}{$\begin{array}{l}\text { TOTAL } \\
(\mathrm{N}=33)\end{array}$} \\
\hline & $\mathrm{N}$ & B & $\mathrm{N}$ & B & $\mathrm{N}$ & B & $\mathrm{N}$ & B \\
\hline $\begin{array}{l}\text { Give a talk for other members of } \\
\text { my organization on workshop } \\
\text { topics }\end{array}$ & 11 & 138 & 5 & 54 & 3 & 79 & 17 & 271 \\
\hline $\begin{array}{l}\text { Replicate the workshop for } \\
\text { members of my organization }\end{array}$ & 2 & 8 & 4 & 55 & 2 & 36 & 8 & 99 \\
\hline $\begin{array}{l}\text { Give a talk or workshop for } \\
\text { members of other organizations }\end{array}$ & 4 & 130 & 1 & NA & 1 & 16 & 6 & 146 \\
\hline $\begin{array}{l}\text { Trained counselors, physicians } \\
\text { or other staff to provide } \\
\text { information to women in need }\end{array}$ & 10 & 85 & 1 & 15 & 2 & 3 & 13 & 103 \\
\hline $\begin{array}{l}\text { Disseminate through the media EC } \\
\text { topics }\end{array}$ & 2 & $\begin{array}{l}2 \\
r d\end{array}$ & 0 & - & 2 & $4 / 1$ & 4 & 6 \\
\hline $\begin{array}{l}\text { Provide verbal information on } \mathrm{EC} \\
\text { to women in need }\end{array}$ & 15 & 118 & 5 & 58 & 3 & 69 & 23 & 248 \\
\hline $\begin{array}{l}\text { Provide EC brochure to rape } \\
\text { victims or women who have had } \\
\text { unprotected sex }\end{array}$ & 13 & 228 & 7 & 103 & 2 & 80 & 22 & 411 \\
\hline $\begin{array}{l}\text { Conducted meetings to discuss } \\
\text { the implementation of EC } \\
\text { activities in the organization. }\end{array}$ & 7 & 49 & 4 & 13 & 3 & 8 & 14 & 70 \\
\hline $\begin{array}{l}\text { Notes: } N=\text { Number of respondents; } \\
\text { activities (persons informed or t } \\
\text { not available; rd=radio; /1: only } \\
\text { number of beneficiaries. }\end{array}$ & 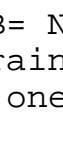 & $\begin{array}{l}\text { oer } \\
\text { wo } \\
\text { espc }\end{array}$ & & $\begin{array}{l}2 \mathrm{n} \\
\mathrm{cov} i\end{array}$ & & $\begin{array}{l}\text { of } t \\
\text { ion, } \\
\text { orma }\end{array}$ & $\begin{array}{l}\text { e } \\
\text { etc) } \\
\text { ion }\end{array}$ & $\begin{array}{l}\mathrm{NA}- \\
\text { on }\end{array}$ \\
\hline
\end{tabular}

In some cases, several participants from one organization responded the questionnaire. If two or more questionnaires provided the same data, only the data from one questionnaire was used. If different data was presented, then it was assumed that the respondent had included information of her or his own activities and was added. As it can be observed in Table 2, a large 
proportion of participants had conducted different activities in the weeks following the workshop, including making available the information to others in their own organizations, given talks in other organizations, conducted meetings to explore how to institutionalize the use of emergency contraception and given information on emergency contraception to women who needed it.

An analysis of the questionnaires from an institutional point of view showed that of the six AGOs who participated, six were giving verbal information and brochures to rape victims, and one more was giving only verbal information. Of the six NGOs who participated in the workshop, four had already given verbal information and brochures to women in need. Finally, of the four participants from other type of organizations (MOH in Veracruz, the IPAS representative in Mexico, and two fellows of the Latin American Women=s Health Network from Brazil and Chile, three claimed to have given verbal information to women and two to have handed out brochures.

Except for three participants who said they had had problems, all the respondents said the activities they had conducted had been well received. In all three cases, the association that some users made with abortion was mentioned. When asked what they had liked most of the workshop, the participants mentioned mainly the organization and treatment of the participants, the presentations of Drs Schiavon and Garza, the novelty of the topic and the materials that were handed out. Least liked things were a few presentations, the tendency of some participant to consider emergency contraception as an abortifacient and their apparent reluctance to use it, and the fact that the workshop was held in one single day and it was too long.

Finally, in the questionnaire, participants were asked if they had any activities scheduled in the near future, with defined dates, place and participants. As it can be seen, at least one half of the participants had scheduled talks, replication of workshops, training of personnel, mass media messages, and providing information on emergency contraception to women in need. 
TABLE 3

\section{NUMBER OF PARTICIPANTS WHO HAVE PROGRAMMED EMERGENCY CONTRACEPTION ACTIVITIES BY TYPE OF ORGANIZATION OF THE END-OF-PROJECT PARTICIPANT}

\begin{tabular}{|l|c|c|c|c|}
\hline \multirow{2}{*}{ ACTIVITY } & \multicolumn{3}{|c|}{ TYPE OF ORGANIZATION } \\
\cline { 2 - 5 } & $\begin{array}{c}\text { USTICE } \\
\text { (N=19) }\end{array}$ & $\begin{array}{c}\text { FEMINIST } \\
\text { (N=10) }\end{array}$ & $\begin{array}{c}\text { OTHER } \\
\text { (N=4) }\end{array}$ & $\begin{array}{c}\text { TOTAL } \\
\text { (N=33) }\end{array}$ \\
\hline $\begin{array}{l}\text { Give a talk for other members of my } \\
\text { organization on workshop topics }\end{array}$ & 7 & 5 & 3 & 15 \\
\hline $\begin{array}{l}\text { Replicate the workshop for members } \\
\text { of my organization }\end{array}$ & 7 & 5 & 3 & 15 \\
\hline $\begin{array}{l}\text { Give a talk or workshop for members } \\
\text { of other organizations }\end{array}$ & 4 & 4 & 2 & 10 \\
\hline $\begin{array}{l}\text { Train counselors, physicians or } \\
\text { other staff to provide information } \\
\text { to women in need }\end{array}$ & 11 & 2 & 3 & 16 \\
\hline $\begin{array}{l}\text { Disseminate through the media EC } \\
\text { topics }\end{array}$ & 8 & 1 & 4 & 13 \\
\hline $\begin{array}{l}\text { Provide information on emergency } \\
\text { contraception to women in need }\end{array}$ & 17 & 7 & 4 & 28 \\
\hline
\end{tabular}

\section{RECAPITULATION}

This project sought to test the acceptability of emergency contraception as an element in the care of rape victims and to extend its use in this context. At the beginning, we faced great reluctance from all organizations to implement the project. At the Federal District's Attorney General Office, it took more than six months of conversations and a substitution of the General Director for the Assistance of Victims to be able to begin project activities. Conversations to open $\mathrm{MOH}$ referral centers for rape victims failed despite our persistence. Once the project begun, the psychologists were reluctant to provide the information to women and their supervisors were reluctant to order them in written form to conduct the activities. This reluctance stemmed from the fact that the treatment is taken after the sexual relation and, thus, is immediately associated with abortion, which is illegal in Mexico. Even when it might be understood that emergency contraception is not abortion, the perception that using it can lead to legal problems remains. Nonetheless, once a few brave psychologists started providing the information to women and their gratefulness and the absence of negative incidents was observed, emergency contraception became a routine element in the care of victims. During the course of 
this project, 82 women were provided the information and perhaps about eight unwanted pregnancies were prevented.

During this project, a very large effort to scale up the strategy was made. As mentioned before, conversations with the $\mathrm{MOH}$ to establish referral centers lead nowhere. The value of NGOs was again proven when MEXFAM decided to provide its support in establishing referral centers and sponsoring the brochure. CEPARH and SIPAM were also eager to join the project.

Workshops to train the staff of different organizations showed us that, as always, a key element in the introduction of emergency contraception is the support from top management. In the states of Coahuila and Hidalgo, a large number of staff members of the AGOs, the MOH and NGOs were trained. However, whereas in Hidalgo the General Director for the Assistance of Victims took an enthusiastic lead in the implementation of the strategy in all public ministry agencies in her state, in Coahuila no such leadership became apparent and little progress in the implementation of activities was observed after the workshop.

The end-of-project workshop showed that gathering a large number of organizations that provide services to raped women was a good strategy, specially because by that time we could already count on the participation of several organizations that could share their experience. As a consequence, the workshop seems to have had a very strong impact on the introduction of emergency contraception as an element in the care of rape victims. Two months after the end-ofproject workshop, the AGOs of the Federal District and the states of Hidalgo, Tlaxcala, Morelos, Oaxaca, Veracruz and Mexico, as well as eight NGOs (MEXFAM, CEPAHR, SIPAM, ADIVAC, AVISE, FAVI, COVAC, COPAS and Sí Mujer) were providing emergency contraception services to victims of abuse. Project statistics of organizations who received direct training shows that 93 women had been provided emergency contraception, whereas data from the end-of-project workshop follow-up questionnaire show that 248 women had been verbal information and 411 were given the brochure. However, several organizations had not yet returned the evaluation questionnaire and it is likely that these numbers sub-estimate both the number of organizations providing EC information and the number of beneficiaries from these activities.

Finally, this project showed that regardless of whether information on emergency contraception is provided to women or not, often those who come in contact with this information are sufficiently interested in it to further disseminate it. This was a constant occurrence in this project, both from organizations as well as from individuals participating in the workshops. 


\section{APPENDICES}

Appendix 1: Project Brochure

Appendix 2: Counseling Guide for Psychologists

Appendix 3: Support Therapy Center AFirst Contact@ Form

Appendix 4: Pre-training Questionnaire

Appendix 5: Reference Clinics and Physicians

Appendix 6: Letter for Dissemination Through E-mail

Appendix 7: News Items and Letters to the Editors

Appendix 8: Alternativas Issue with EC Brochure

Appendix 9: End-of-project Follow-up Evaluation Questionnaire

1. Consensus statement on emergency contraception. Contraception 52, pp 211-213, October 1995.

2. IPPF Medical Bulletin. IMAP Statement on emergency contraception. Volume 28, No. 6, December 1994. 2. Consensus statement on emergency contraception. Contraception 52, pp 211213, October 1995.

2. IPPF Medical Bulletin. IMAP Statement on emergency contraception. Volume 28, No. 6, December 1994. 